\title{
PHARMACY STUDENTS' FEEDBACK ABOUT OBJECTIVE STRUCTURED PRACTICAL EXAMINATION (OSPE) AFTER THE PHARMACEUTICAL CARE COURSE IN POLAND
}

\author{
JUSTYNA DYMEK ${ }^{1}$, TOMASZ MATEUSZ KOWALSKI ${ }^{1 *}$, AGNIESZKA SKOWRON ${ }^{1}$, \\ MICHAL NOWAKOWSKI ${ }^{2}$, and ANNA GOLDA ${ }^{1}$
}

\author{
${ }^{1}$ Department of Social Pharmacy, Faculty of Pharmacy, Jagiellonian University Medical College, \\ Medyczna 9, 30-688 Krakow, Poland \\ ${ }^{2}$ Department of Medical Education, Jagiellonian University Medical College, \\ Medyczna 7, 30-688 Krakow, Poland
}

\begin{abstract}
An important part of the pharmaceutical study program is a thorough assessment of students' skills. The new form of assessing skills in pharmacy teaching is the Objective Structured Practical Examination (OSPE). The purpose of this study was the assessment from students on the preparation, organization, and conduct of the OSPE examination and analyze students' suggestions to improve future OSPE exams' quality and improve the Pharmaceutical Care course's teaching method (PCc). The study was conducted at the Faculty of Pharmacy of the Jagiellonian University Medical College in the winter semesters in the academic years 2018-2019 and 2019-2020. The study was attended by students of the $5^{\text {th }}$-year of pharmacy who took the OSPE for the first time. After the exam, students filled in an anonymous questionnaire about their general approach to the OSPE. They assessed each station and the selfassessment. The results were analyzed by performing statistical analyses and compared between years. A total of $1835^{\text {th }}$-year pharmacy students participated in the study, including 108 students in the 20182019 academic year and 75 students in the 2019-2020 academic year. Half of the students had a positive attitude towards OSPE, but the vast majority stated that the OSPE was stressful. Over $70 \%$ of students assessed that stations with simulated patients create real situations in pharmacy. Pharmacy students rated the OSPE exam as a reliable tool for assessing their skills.
\end{abstract}

Keywords: Objective Structured Practical Examination, pharmacy education, student's feedback, assessment

Today's challenge in teaching in pharmacy is to provide graduates with the knowledge and skills that will allow them to deliver pharmaceutical services in the right way. Pharmacy curricula at universities are changed to achieve these objectives, emphasizing skills development (1). For this reason, the assessment of skills is a crucial element of evaluation in the medical and pharmaceutical curricula worldwide. National standards describe learning outcomes that are gained by students while studying pharmacy. Knowledge should be balanced by skills in curricula, as both prepare students for their working lives (2).

Usually, knowledge is verified in a traditional way (e.g., multiple, single choice tests, descriptive reports) (3). Skills in the pharmacy profession are fundamental aspects. Therefore, some universities have implemented in their assessment systems appropriate tools to test specific skills. For some time in pharmaceutical education so-called Objective Structured Practical Exam (OSPE) is used to assess skills (including manual, interpersonal, and communication skills). Some studies indicated that $37 \%$ of US universities that educate future pharmacists use the OSPE extensively to assess students' skills (4). The OSPE has become a good assessment tool and has been marked as a gold standard tool to assess students' skills around the world (5-7). A well-constructed and implemented OSPE is the key to achieve the correct and reliable assessment of skills (8-11).

The OSPE is conducted with simulated patients' participation in standardized conditions (12). The OSPE requires that each student demonstrates specific skills and attitudes in simulated conditions. It consists of several stations where students' practical competencies are assessed. Students during the OSPE have a defined time to perform all activities.

* Corresponding author: e-mail: tomek.kowalski@doctoral.uj.edu.pl 
The duration of the station ranges from several to several dozen minutes. An objective grading system is used to assess students (2). Examiners play a key role in running the OSPE. Research indicates that the examiners participating in the OSPE and student assessment agree that the OSPE assesses skills, while $<50 \%$ believe that it also tests knowledge. The authors of other publications, based on their experience, believe that the OSPE is a crucial tool for assessing skills in patient care, interpersonal and communication skills $(13,14)$.

For the first time in Poland, the OSPE was implemented and conducted at the end of the Pharmaceutical Care course (PCc) at the Faculty of Pharmacy of the Jagiellonian University Medical College. It was based on the experience of the Faculty of Medicine of the Jagiellonian University Medical College, where the OSCE was implemented for the first time in medical education in Poland (15). The OSPE in pharmacy education consisted of stations that checked acquired knowledge and skills following the learning outcomes contained in the syllabus for PCc. The exam organizers analyzed the learning outcomes skills and separated pharmaceutical services. They created six stations: pharmaceutical interview, advice for self-medication, education about medicines, medical device education, identification, and solving of drug-related problems (DRPs) (16).

The purpose of our study was to evaluate feedback from students who were taking the OSPE exam for the first time about the preparation, organization, and conduct of the exam. The study aimed to assess and analyze students' suggestions to improve the OSPE exams' quality and improve the PCc.

\section{EXPERIMENTAL}

\section{Methods}

The study was conducted at the Faculty of Pharmacy of the Jagiellonian University Medical College in the winter semesters in the academic years 2018-2019 and 2019-2020. A self-designed questionnaire by the team was voluntary and anonymous. It was targeted at the senior ( $5^{\text {th }}$ year) pharmacy students (5.5-year master's program) who took the OSPE for the first time. Both exams and the surveys in 2018-2019 and 2019-2020 were carried out in the same way. The number and type of stations and scenarios did not change. The assessment questionnaires, academic teachers working as examiners, the rules of the exam, and instructions at individual stations have not changed. Some classes in PCc in 20192020 were conducted using the PBL (Problem-Based
Learning) method. The difference in the teaching method used during the PCc is the only element that might affect the survey results.

\section{Tools of data collection}

The tool for collecting data was a paper questionnaire allowing to express opinions and collect students' assessment of the OSPE. The survey was provided in Polish, and it was internally validated by 5 reviewers. The questionnaire consisted of two parts. The first part concerned the general feelings related to the exam, e.g., whether the student had a positive attitude to the exam, how the exam was organized and did it meet the student's expectations, and if the instructions at the stations were clear and understandable. Students in the questionnaire answered whether the exam allowed them to assess their skills, whether any skills remained uncompleted, and if the OSPE was better than other traditional assessment forms (e.g., written form).

Part I of the questionnaire contained 11 questions and was prepared using the Likert 5-point scale. The respondents defined their attitude to the statements presented in the following way: strongly disagree (SD), disagree (D), neutral (N), agree (A), strongly agree (SA). Table 1 includes all questions from part I of the survey.

Part II of the survey, consisting of 6 questions, concerned the students' self-assessment and their feelings related to the individual station. The respondents indicated all stations (one or more) matched to the given statement, e.g., I expect I was rated high / low at a given station, which station was the most / least stressful for me. Table 2 includes all questions from part II of the survey.

After completing the study, students were able to provide additional comments related to the OSPE.

Students received a questionnaire immediately after the OSPE with a request to fill it in after leaving the examination rooms and throw completed questionnaires into the urn located in the corridor.

\section{Statistical analysis}

The data were analyzed by using the Statistica ${ }^{\mathrm{TM}}$ 12 package. The independent samples T-test were used for statistical analyses. Statistical significance was set at $\mathrm{p}<0.05$.

\section{RESULTS}

108 out of 109 pharmacy students participated in the study in the 2018-2019 academic year and 75 out of 77 students in the 2019-2020 academic year. Researchers analyzed the significance of differences 
Table 1. Pharmacy students' evaluation of the OSPE (part I of the questionnaire).

\begin{tabular}{|c|c|c|c|c|c|c|c|}
\hline \multirow{3}{*}{ Questionnaire statement } & \multicolumn{7}{|c|}{ Responses agree and strongly agree } \\
\hline & \multicolumn{2}{|c|}{$\begin{array}{c}\text { all } \\
\mathrm{N}=183\end{array}$} & \multicolumn{2}{|c|}{$\begin{array}{c}2018-2019 \\
N=108\end{array}$} & \multicolumn{2}{|c|}{$\begin{array}{l}2019-2020 \\
N=75\end{array}$} & \multirow{2}{*}{$\mathrm{p}$} \\
\hline & $\mathrm{N}$ & $\%$ & $\mathrm{~N}$ & $\%$ & $\mathrm{~N}$ & $\%$ & \\
\hline Positive about the OSPE before it & 92 & 50.3 & 60 & 55.5 & 32 & 42.7 & 0.044 \\
\hline The OSPE meet expectations & 137 & 74.9 & 84 & 78.0 & 53 & 70.7 & 0.13 \\
\hline $\begin{array}{l}\text { Information about the organisation and conduct of the exam } \\
\text { were understandable }\end{array}$ & 155 & 84.7 & 95 & 88.0 & 60 & 80.0 & 0.69 \\
\hline $\begin{array}{c}\text { Information about the organization and conduct of the exam } \\
\text { were sufficient }\end{array}$ & 144 & 78.7 & 84 & 93.0 & 57 & 76.0 & 0.0006 \\
\hline Instructions on stations were clear and understandable & 162 & 88.5 & 96 & 89.0 & 66 & 88.0 & 0.42 \\
\hline $\begin{array}{l}\text { Stations with simulated patient gave the feeling of real } \\
\text { situations in pharmacy }\end{array}$ & 143 & 78.1 & 80 & 74.0 & 63 & 84.0 & 0.054 \\
\hline $\begin{array}{c}\text { The program of the PCc allow to prepare to the OSPE } \\
\text { adequately }\end{array}$ & 107 & 58.5 & 64 & 59.0 & 43 & 57.3 & 0.11 \\
\hline Exam helped to assess skills better & 132 & 72.1 & 72 & 66.0 & 60 & 80.0 & 0.019 \\
\hline The OSPE helped to recognize issues for further study & 138 & 75.4 & 32 & 30.0 & 63 & 84.0 & $<0.0001$ \\
\hline $\begin{array}{l}\text { The OSPE is better than the traditional form of assessment } \\
\text { (ex. written exam) }\end{array}$ & 123 & 67.2 & 81 & 75.0 & 42 & 56.0 & 0.0035 \\
\hline The OSPE was stressful & 139 & 76.0 & 74 & 68.0 & 65 & 86.7 & 0.0019 \\
\hline
\end{tabular}

$\mathrm{PCc}=$ Pharmaceutical Care course; OSPE $=$ Objective Structured Practical Examination

Table 2. Students' self-assessment of achievement on the exam and their evaluation of PCc (part II of the questionnaire).

\begin{tabular}{|c|c|c|c|c|c|c|c|}
\hline Station & & $\begin{array}{l}\text { I expect that } \\
\text { I will be } \\
\text { highly rated }\end{array}$ & $\begin{array}{l}\text { I expect that } \\
\text { I will be } \\
\text { low-rated }\end{array}$ & $\begin{array}{c}\text { The most } \\
\text { stressful } \\
\text { station }\end{array}$ & $\begin{array}{c}\text { The least } \\
\text { stressful } \\
\text { station }\end{array}$ & $\begin{array}{c}\text { PCc } \\
\text { prepared } \\
\text { me the best } \\
\text { to pass the } \\
\text { station }\end{array}$ & $\begin{array}{l}\text { PCc prepared } \\
\text { me the worst } \\
\text { to pass the } \\
\text { station }\end{array}$ \\
\hline \multirow{2}{*}{$\begin{array}{c}\text { Station 1 } \\
\text { Pharmaceutical } \\
\text { interview }^{1}\end{array}$} & 2018-2019 & $60.2 \%$ & $10.2 \%$ & $12.0 \%$ & $52.8 \%$ & $65.7 \%$ & $5.6 \%$ \\
\hline & $2019-2020$ & $56.0 \%$ & $9.3 \%$ & $13.3 \%$ & $54.7 \%$ & $54.7 \%$ & $5.3 \%$ \\
\hline \multirow{2}{*}{$\begin{array}{c}\text { Station } 2 \\
\text { Advice for } \\
\text { self- medication }{ }^{1}\end{array}$} & 2018-2019 & $30.6 \%$ & $18.5 \%$ & $25.9 \%{ }^{\mathrm{a}}$ & $12.0 \%$ & $22.2 \%$ & $26.9 \%$ \\
\hline & $2019-2020$ & $28.0 \%$ & $26.7 \%$ & $37.3 \% \%^{\mathrm{a}}$ & $5.3 \%$ & $28.0 \%$ & $21.3 \%$ \\
\hline \multirow{2}{*}{$\begin{array}{c}\text { Station } 3 \\
\text { Education about } \\
\text { medicines }^{1}\end{array}$} & 2018-2019 & $43.5 \%{ }^{\mathrm{b}}$ & $13.9 \%$ & $13.0 \%$ & $22.2 \% \%^{\mathrm{a}}$ & $18.5 \%$ & $18.5 \% \%^{\mathrm{a}}$ \\
\hline & $2019-2020$ & $24.0 \%{ }^{\mathrm{b}}$ & $22.7 \%$ & $17.3 \%$ & $9.3 \%^{\mathrm{a}}$ & $13.3 \%$ & $32.0 \% \%^{\mathrm{a}}$ \\
\hline \multirow{2}{*}{$\begin{array}{c}\text { Station } 4 \\
\text { Medical device } \\
\text { education }{ }^{1}\end{array}$} & 2018-2019 & $45.4 \% 0^{\mathrm{b}}$ & $11.1 \% \%^{\mathrm{a}}$ & $23.2 \%$ & $25.0 \%$ & $25.9 \%$ & $18.5 \%{ }^{\mathrm{a}}$ \\
\hline & $2019-2020$ & $22.7 \%$ b & $21.3 \% \%^{\mathrm{a}}$ & $32.0 \%$ & $21.3 \%$ & $20.0 \%$ & $30.7 \%{ }^{\mathrm{a}}$ \\
\hline \multirow{2}{*}{$\begin{array}{c}\text { Station } 5 \\
\text { Identification } \\
\text { of drug-related } \\
\text { problems }^{2}\end{array}$} & 2018-2019 & $9.3 \%$ & $63.0 \%$ & $44.4 \%$ & $7.4 \%$ & $30.6 \%$ & $28.7 \%$ \\
\hline & $2019-2020$ & $6.7 \%$ & $60.0 \%$ & $46.7 \%$ & $13.3 \%$ & $22.7 \%$ & $25.3 \%$ \\
\hline \multirow{2}{*}{$\begin{array}{c}\text { Station } 6 \\
\text { Drug-related } \\
\text { problems solving }\end{array}$} & 2018-2019 & $18.5 \%$ & $38.9 \% \%^{\mathrm{a}}$ & $20.4 \%$ & $18.5 \%{ }^{\mathrm{a}}$ & $40.7 \% \%^{\mathrm{a}}$ & $17.6 \%$ \\
\hline & $2019-2020$ & $16.0 \%$ & $26.7 \% \%^{\mathrm{a}}$ & $20.0 \%$ & $30.7 \% \%^{\mathrm{a}}$ & $24.0 \% \%^{\mathrm{a}}$ & $9.3 \%$ \\
\hline
\end{tabular}

${ }^{\mathrm{a}} \mathrm{p}<0.05 ; \mathrm{b} \mathrm{p}<0.005 ; \mathrm{PCc}=$ Pharmaceutical Care Course; OSPE $=$ Objective Structured Practical Examination ${ }^{1}$ Station 1-4 - stations with simulated patients

${ }^{2}$ Stations 5-6 - stations with documentation 
Table 3. Comparison of average scores for all students in the 2018-2019 and 2019-2020 academic years for sic stations.

\begin{tabular}{|c|c|c|c|c|c|c|}
\hline \multirow{2}{*}{ Station } & \multicolumn{2}{|c|}{ 2018-2019 } & \multicolumn{2}{|c|}{$2019-2020$} & \multirow{2}{*}{$\mathrm{t}$} & \multirow{2}{*}{$\mathrm{p}$} \\
\hline & Mean score & SD & Mean score & SD & & \\
\hline $\begin{array}{c}\text { Station } 1 \\
\text { Pharmaceutical interview }\end{array}$ & 72.0 & 11.65 & 75.9 & 12.40 & 2.16 & 0.032 \\
\hline $\begin{array}{c}\text { Station } 2 \\
\text { Advice for self- medication }\end{array}$ & 65.9 & 11.13 & 67.7 & 13.41 & 0.98 & 0.330 \\
\hline $\begin{array}{c}\text { Station } 3 \\
\text { Education about medicines }\end{array}$ & 73.7 & 11.91 & 69.3 & 12.95 & -2.37 & 0.019 \\
\hline $\begin{array}{c}\text { Station } 4 \\
\text { Medical device education }\end{array}$ & 65.1 & 11.16 & 64.7 & 11.95 & -0.26 & 0.792 \\
\hline $\begin{array}{c}\text { Station } 5 \\
\text { Identification of DRPs }\end{array}$ & 59.4 & 16.53 & 58.5 & 14.72 & -0.38 & 0.705 \\
\hline $\begin{array}{c}\text { Station } 6 \\
\text { DRPs solving }\end{array}$ & 69.3 & 19.67 & 71.2 & 14.42 & 0.72 & 0.470 \\
\hline
\end{tabular}

DRPs - drug-related problems

for structural indicators (percentages) of the first part of the questionnaire in the specific years (Table 1). Table 1 shows the questions included in the survey in Part I, together with information on how many students agreed with the declaration (agree / strongly agree). Over $80 \%$ of students indicated that the exam and instructions for individual stations were clear and understandable. The course of the exam was as expected by over $70 \%$ of students.

In the 2018-2019 academic year, about 56\% of students had a positive attitude towards the OSPE before it began, and in the 2019/2020 academic year, only $43 \%$ of students had a similar opinion ( $\mathrm{p}=$ 0.044 ). Over $86 \%$ of students from $2019-2020$ admitted that the exam was stressful, but at the same time, students declared that the OSPE helped them assess their skills (80\%) and recognize issues for further study (84\%). Significantly fewer students from 2018-2019 agreed with these statements $(68 \%, 66 \%$, $30 \%$, respectively).

Table 2 contains the questions included in the second part of the study and information on what percentage of students agreed with each station's statement. Over $60 \%$ of students from the 2018/2019 academic year and over 50\% from 2019/2020 expected to be highly rated at station 1 (Pharmaceutical interview) and indicated that the PCc prepared them the most to pass this station. Students showed this station as the least stressful for them (over $50 \%$ of respondents). Over $60 \%$ of students chose station 5 (Identification of drug-related problems), expecting it to be rated the least and as the most stressful station (over 40\%).

Table 3 shows standardized points (100 points per station) obtained by students at individual stations. The highest average scores for all students were obtained at station 1 (Pharmaceutical interview), station 3 (Education about medicines) (20182019), and station 6 (Drug-related problems solving) (2019-2020). Students obtained the lowest average number of points at station 5 . The average of ratings for station 1 was statistically significantly higher in 2019-2020 compared to the results from 2018-2019. Similarly, the average of ratings at station 3 in 20182019 was statistically significantly higher than in 2019-2020. The twenty survey forms contained additional student comments (posted under the survey). Students in this place most often (19/20 comments) referred to the time provided for the exam. The comments prevailed that the time provided for station 5 and station 6 was too short (stations with documentation). Students had no objections to the exam duration at stations 1-4 (stations with the simulated patient).

\section{DISCUSSION}

The Objective Structured Clinical Examination (OSCE) and Objective Structured Practical Examination (OSPE) are a method of objectively testing the clinical and practical knowledge and skills, assessing many students in a short period (17). OSCE assesses clinical knowledge, skills, and attitudes such as history taking, physical examination, simple procedures, interpretation of lab results, patient management problems, communication, attitude (18). OSCE is using in medicine or dentistry (19). In pharmacy, the emphasis is on practical skills. Clinical skills are taught and tested to a lesser extent (20). Therefore, in our Faculty, we conduct an examination under the name OSPE. Despite that one difference, the setting up of the OSCE and OSPE, their course, and their 
purpose are the same. Therefore, some authors use these names interchangeably (21). Due to the small number of articles describing OSPE, and the lack of differences between OSPE and OSCE, when discussing our results, we refer to articles also describing OSCE.

The study was conducted among $5^{\text {th }}$-year pharmacy students who took the OSPE for the first time. An anonymous survey on the preparation, organization, and conduct of the OSPE was chosen as a tool to learn students' opinions about the exam.

The literature indicates the usefulness of such a tool for modification and quality improvement of the OSPE. It gives opportunities to improve and develop the OSPE. Student feedback after the exam may contribute to changes in the manner and form of teaching (21-23). In our study, most students (67.2\% of all students surveyed) recognized that they prefer the OSPE to other traditional assessment methods, including a written form. A similar opinion was noticed in other studies, which may be related to the documented objectivity and credibility of the OSPE (24-26). Our study also confirmed that pharmacy students accept this form of the exam in assessing skills. Positive opinions have already appeared in the literature on this acceptability of the OSPE among medical students $(27,28)$.

Seventy-five percent of students in our study agreed that the OSPE, due to its form, allows them to assess their skills and identify areas that require them to supplement their knowledge. Similar results were obtained by Yaqinuddin et al (29) in a study, where $74 \%$ of students admitted that the exam allowed them to verify what they should supplement and improve in terms of their knowledge and skills in the field of anatomy. Other articles in the literature confirm that the OSPE, due to its form, is considered a good, valuable tool for assessing students' skills (26-28). For $76 \%$ of students participating in our study, the exam was stressful. Due to similar conditions for conducting the exam and the fact that the OSPE was carried out for the first time, our result can be compared with the Manjula et al. study results. Students' opinions appeared for the stressful nature of the exam (27). Manjula pointed out that this fact can cause stress for students. In 2019-2020 the OSPE, after PCc was conducted for the second time for examiners, for the students joining, it was still a new form of exam, previously not practiced at our faculty. However, the results showed by Martin et al. suggest a lack of association between anxiety and student performance. It could be valuable in the future to assess the total level of anxiety among students taking OSPE after the PCc at our Faculty (30).
Wadde et al. made quite the opposite conclusions in a study in which students participating in the OSPE found that the exam was not stressful for them, while the examiners were experiencing stress (31). In our study, some students admitted that the time allocated to perform tasks at stations 5 and 6 was insufficient for them, with no comments related to the exam duration at the other four stations. Similar feelings of students appear in the study of Manjula et al., where for $60 \%$ of students, the exam time could be longer. In the Chandelkar study, only $0.69 \%$ of students were unhappy with the time allocated for the OSPE. In the Deshpande study, every student $(100 \%)$ admitted that sufficient time was given to each student $(24,28)$.

The issues related to time at individual stations in our study are not so obvious. While students scored the lowest average number of points at station 5 , they scored $70 \%$ on average at station $6\left(2^{\text {nd }}\right.$ best result). This may be since students taking our exam do not have time management experience in this assessment form. Wadde et al. also pointed to this problem in their observations (31).

Some differences in the evaluation were observed between both groups of students (Table 1), which could not be easily explained. For example, despite the fact that both groups of students were given the same information about organizational and technical aspects of the exam, we observe the difference between students' opinions about it 93\% vs. 76\% (in 2018-2019 and 2019-2020, respectively) strongly agree/agree that the information was sufficient. Unfortunately, we could not find any reason for such difference, except the student's individual preferences. Because both groups received the exact content of information about organizational and technical aspects of the exam, the information was distributed using the online platform, the same they used during the PCc, which they are familiar with, because it is the main online platform at the university and is commonly used to communicate with students, also during all courses conducted by our team. Additionally, for both groups, about one month before the exam, a short face-to-face meeting with the Head of Department (AS) was organized so that students could ask for information and explanation.

One of the limitations of our study is the fact that it is the very early experience of such type of pharmacy students' assessment in Poland, and the Faculty of Pharmacy of the Jagiellonian University Medical College is the only one, which uses it, so the results could not be easily related to the opinion of pharmacy students in Poland about the OSPE. 
Due to the anonymous type of survey, it was not possible to compare the specific student's opinion with his/her results at the OSPE, as well as it was not possible to find a strict correlation among specific factors. However, it should also be mentioned that the decision about the anonymous type of survey was intentional, as it, in our opinion, gave a higher probability of obtaining the real and honest opinion from the students.

\section{CONCLUSIONS}

Fifth-year pharmacy students positively evaluated the OSPE as a method of assessing skills, reflecting real situations in the pharmacy. They also found that they prefer the OSPE to other traditional assessment methods, but most students said that the OSPE form was stressful. In their comments on the quality of the OSPE, students referred primarily to the time provided for individual stations' solutions. The results of the study suggest the continuation of the OSPE in the future.

\section{Acknowledgments}

Not applicable.

\section{Conflicts of interest}

The authors declare that there are no conflicts of interest.

\section{REFERENCES}

1. Hepler CD.: Pharmacotherapy 24, 1491 (2004).

2. Kowalski T., Skowron A., Nowakowski M.: Indian J. Pharm. Educ. Res. 53, 186 (2019).

3. Almuqdadi A., Yousef A.M., Majdalawi K., Masoud Z., Kalabani R., Al-Hadeed H.: Indian J. Pharm. Educ. Res. 51, 380 (2017).

4. Sturpe D.A., Huynh D., Haines S.T.: Am. J. Pharm. Educ. 74, 5 pages (2010).

5. Patrício M.F., Julião M., Fareleira F., Carneiro A.V.: Med. Teach. 35, 503 (2013).

6. Rushforth H.E.: Nurse Educ. Today 27, 481 (2007).

7. Pierre R.B., Wierenga A., Barton M., Branday J.M., Christie CDC.: BMC Med. Educ. 4, 1 (2004).

8. Baruah M.N.: J. Med. Sci. Clin. Res. 7, 947 (2019).
9. Corbo M., Patel J.P., Tawab R.A., Davies J.G.: Pharm. Educ. 6, 53 (2006).

10. Awaisu A., Rahman N.S.A., Mohamed M.H.N., Bux S.H.B.R., Nazar N.I.M.: Am. J. Pharm. Educ. 74, (2010).

11. Curtis S., Smith K.J., Taylor J.: Curr. Pharm. Teach. Learn. 11, 832 (2019).

12. Bayoumy H.M.M., Yousri H.: J. Am. Sci. 8, 523 (2012).

13. Chan C.Y.: J. Chin. Med. Assoc. 74, 193 (2011).

14. Varkey P., Natt N., Lesnick T., Downing S., Yudkowsky R.: Acad. Med. 83, 775 (2008).

15. Skrzypek A., Szeliga M., Stalmach-Przygoda A., et al.: Folia Med. Cracov. 57, 67 (2017).

16. Dymek J., Kowalski T., Golda A., Polak W., Skowron A.: Indian J. Pharm. Educ. Res. 54, 572 (2020).

17. Radhika G., Dara A.K., Varalaxmi K.P., Bhavani C.: J. NTR Univ. Health Sci. 4, 145 (2015).

18. Zayyan M.: Oman Med. J. 26, 219 (2011).

19. Puryer J.: Dent. J. 4, 6 (2016).

20. Malhotra S.D., Shah K.N., Patel V.J.: J. Educ. Health Promot. 2, 53 (2013).

21. Nasir N., Asad M.R., Sami W., Amir K.M.: J. Adv. Res. 3, 535 (2015).

22. Rao R.D., Babu P.U., Chakravarthy K.C.V., Ramya N.: Int. J. Res. Med. Sci. 6, 221 (2018).

23. Guirguis F., Andrade R., Beck C., Ellen D., Slivecka J., Richard C.L.: Curr. Pharm. Teach. Learn. 12, 302 (2020).

24. Chandelkar U.K., Rataboli P.V., Samuel L.J., Kamat A.S., Bandodkar L.V.: Int. J. Sci. Rep. 1, 113 (2015).

25. Ranjan R., Jain A., Bhujade R.: Int. J. Anat. Res. 4, 1789 (2016).

26. Branch C.: Curr. Pharm. Teach. Learn. 6, 22 (2014).

27. Manjula A., Shashikala P., Nagaraj P.: J. Med. Educ. Res. 1, 12 (2013).

28. Deshpande R., Motghare V., Padwal S., Bhamare C., Rathod S., Pore R.: Int. J. Basic Clin. Pharmacol. 2, 629 (2013).

29. Yaqinuddin A., Zafar M., Ikram MF., Ganguly P.: Anat. Sci. Educ. 6, 125 (2013).

30. Martin R.D., Naziruddin Z.: Curr. Pharm. Teach. Learn. 12, 1491 (2020).

31. Wadde S.K., Desphande R.H., Madole M.B., Pathan F.J.: Sch. J. App. Med. Sci. 1, 348 (2013). 